\title{
Structural, Optical and Photo Catalytic Properties of CdS Thin Films Synthesized by Green-CBD Method
}

\author{
V.J. Sawant ${ }^{1, \star}$, D.A. Lavate ${ }^{2}$, A.S. Khomane ${ }^{2}$
}

Aim of this work is to study the synthesis of CdS thin films by eco-friendly rout and analyze the change in structural and optical properties of material due to use of biomolecules as a stabilizing agent. The CdS thin films were deposited in lemon extract and ammonia solution separately by maintaining the same physical parameters and analyzed for tailoring of structural and optical properties. Green-CBD method minimizes the use of toxic precursors and volatilization of ammonia solution. X-Ray Diffraction study indicates formation of face centered cubic crystalline phase predominantly for CdS thin films materials with change in grain size. SEM analysis revealed the formation of CdS nanospheres in ammonia while CdS nanocubes in lemon extract. The direct allowed band gap energy was observed in the order of $2.45 \mathrm{eV}$ and $2.25 \mathrm{eV}$ which were interesting for optical studies. UV-Vis Absorption spectra and PL spectra of thin films indicates the CdS thin film material has absorption maxima in visible $(400-800 \mathrm{~nm})$ region. As synthesized CdS thin films were applied for photodegradation of Rhodamine-B dye solution under sunlight. The CdS thin film material deposited by Green-CBD rout shows high efficiency for degradation of Rhodamine-B solution as compared to films deposited by CBD method.

\section{Introduction}

In last two decades the metal oxides, metal sulphides and composite materials has received the greater interest of many researchers due to their considerable properties and use in electronics as well as biotechnology applications. It has been used in optoelectronic devices, solar cell, photovoltaic cells, biotechnology, drug delivery and photocatalytic studies due to their structural and optical properties [1-6]. $\mathrm{Sb}_{2} \mathrm{~S}_{3}$ and $\mathrm{CeS}$ thin film material has been synthesized by CBD method at variable $\mathrm{pH}$ shows considerable optical band gap energies, surface tension and electrical resistivity with respect to films thickness as used in optoelectronic devices [4]. The CuS thin film material deposited by CBD method has considerable refractive index, extinction and dielectric coefficient [5-7]. Metal sulfide Nano crystalline thin films such as $\mathrm{CeS}, \mathrm{PbS}$ and $\mathrm{Bi}_{2} \mathrm{O}_{2} \mathrm{~S}$ were deposited by $\mathrm{CBD}$ in variable $\mathrm{pH}$ environment has great interest due to their optical and refractive properties [8-10]. The transition element doped metal sulfide nanoparticles such CuS-Ni heterojunction can be prepared by hydrothermal method and has applied for

'Department of Chemistry, Rajaram College, Kolhapur 416004 , Maharashtra, India

${ }^{2}$ ATS SBGI Miraj, Sangli 416 410, Maharashtra, India

*Corresponding author:

sawantvikas8877@gmail.com

DOI: 10.5185/amlett.2021.111677 antibacterial biological activity studies [11-13]. The Cadmium sulfide thin films can be prepared by chemical bath deposition, Spray pyrolysis, Successive ionic layer adsorption and reaction (SILAR), hydrothermal and vapor phase deposition methods [14-17]. In chemical bath deposition (CBD) method the synthesis of CdS thin films were carried out with chemicals such as EDTA, thiourea and ammonia solution matrix and reaction to be maintained at high temperature [18]. In CBD method the hazardous effects of such chemicals, handling operation at high temperature and volatilization of ammonia solution, $\mathrm{CdS}$ nanoparticles has been synthesized by green methods. Some researchers reported the use of starch biopolymer as a capping agent during synthesis of CdS nanocrystals [19]. $\mathrm{CdS}$ can be biosynthesized using plant culture and yeast [20]. The use of stabilizing agents during synthesis plays vital role in size confined and controlled growth of nanomaterials. The properties of nanoparticles such as crystallographic phase, size and shape, optical band gap energies can be tailored by use of suitable stabilizing agents during synthesis [21]. Lemon extract can be effectively used as a stabilizing agent for synthesis of metal chalcogenide nanomaterials [22,23]. It is more economical to use lemon extract as a stabilizing agent during CdS thin film deposition at room temperature and use of natural sunlight for photodegradation study.

In this work we reported the biogenic synthesis of $\mathrm{CdS}$ thin films by green chemical dip method using lemon extract (citrus Limon fruit juice) as a stabilizing/capping 


\section{Advanced Materials Letters https://aml.iaamonline.org}

agent. As prepared $\mathrm{CdS}$ thin films with considerable band gap energies were efficiently catalyzes the photodegradation of Rhodamine-B dye solution under natural sunlight irradiation.

\section{Experimental details}

\section{Synthesis of CdS thin films}

The chemicals used were SD fine analytical grade cadmium chloride, sodium sulfide, sodium hydroxide, thiourea, liq. ammonia and de-ionized water. Fresh lemon (citrus Limon) fruits were collected, and it was cuts, squeezed and filtered to get fresh extract. The glass plates of size $75 \times 25 \times 2 \mathrm{~mm}$ were washed in alcohol, chromic acid, and distilled water many times and dried before deposition of thin film sample.

For the synthesis of CdS thin films in ammonia matrix (CBD), $0.1 \mathrm{M}$ cadmium chloride and $0.1 \mathrm{M}$ thiourea solutions were used as precursors for $\mathrm{Cd}^{++}$and $\mathrm{S}^{--}$. Cadmium chloride solution in 1:1 ammonia solution formed cadmium hydroxide which was dissolved in excess ammonia. After addition of equimolar quantities of thiourea, the glass plates were dipped in the solution with constant stirring. Reaction temperature was maintained at $80{ }^{\circ} \mathrm{C}$ and $\mathrm{pH} 10$ was maintained to optimized condition. After $2 \mathrm{hr}$. glass plates with deposition of CdS materials were removed, washed with de-ionized water, and dried at room temperature. The synthesis $\mathrm{CdS}$ thin film in lemon extract (Green-CBD) is carried out in $10 \mathrm{~mL}$ fresh lemon extract by co-precipitation using cadmium chloride $\left(\mathrm{Cd}^{++}\right)$ and sodium sulfide $\left(\mathrm{S}^{-}\right)$solution in equimolar proportion. In reaction mixture sodium hydroxide $(\mathrm{NaOH})$ solution were added drop wise with constant stirring at $400 \mathrm{rpm}$ to get optimize the $\mathrm{pH}$. Biomolecules present in lemon extract stabilizes the growth of $\mathrm{CdS}$ thin film materials at room temperature. The dark yellow colored $\mathrm{CdS}$ nonparticles were successfully deposited on glass substrate.

$$
\begin{aligned}
& \mathrm{CdCl}_{2}+\left(\mathrm{NH}_{2}\right) \mathrm{CS}\left(\mathrm{NH}_{2}\right)+\mathrm{NH}_{3} \stackrel{\Delta / 80^{\circ} \mathrm{C}}{\longrightarrow} \mathrm{CdS} \\
& \mathrm{CdCl}_{2}+\mathrm{Na}_{2} \mathrm{~S}+\text { Lemon extract } \stackrel{\text { Room Temp. }}{\longrightarrow} \mathrm{CdS}
\end{aligned}
$$

Further the glass plates were removed from reaction mixture and washed many times with de-ionized water and kept at room temperature in desiccators for drying [23,24].

\section{Devices and techniques used for characterization and photocatalytic study}

As synthesized $\mathrm{CdS}$ thin films were analyzed for crystallographic identification by JEOL X-ray diffractometer (Model JSDX- 60PA) with $\mathrm{Cu} \mathrm{Ka1-}$ radiation source has wavelength $\lambda=0.154184 \mathrm{~nm}$ and the energy $\mathrm{E}=8.052 \mathrm{keV}$. The $2 \theta$ scan investigated in the range of $20^{\circ}$ to $80^{\circ}$. Cambridge Stereo Scan (USA) Scanning Electron Microscope (SEM) was used for surface morphological analysis of $\mathrm{CdS}$ thin films. Energy dispersive $\mathrm{X}$ ray analysis (EDAX) was carried to determination of atomic percentage composition in $\mathrm{Cd}$ : $\mathrm{S}$ ratio. The optical absorptions were recorded in the wavelength range of 400-800 nm using UV-vis-NIR double beam spectrophotometer (Hitachi-330 Japan). The photocatalytic degradation of Rhodamine-B was investigated by time dependent counting of absorption data under 400-800 $\mathrm{nm}$. For that Shimadzu UV-vis-NIR double beam spectrophotometer (model UV310PC) was used [25].

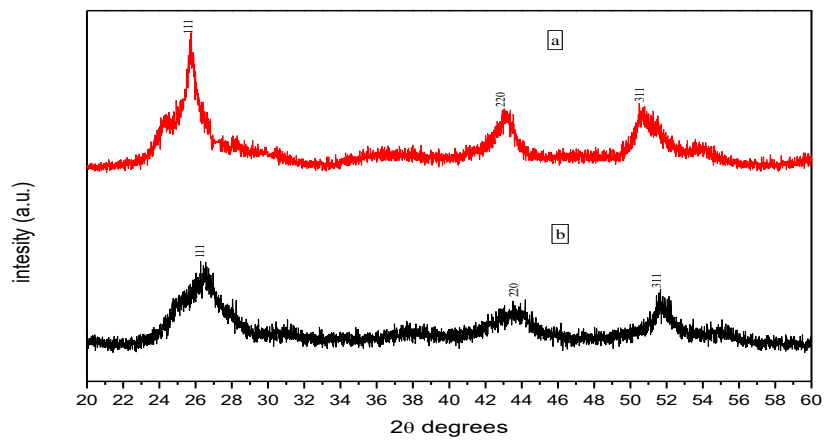

Fig. 1. XRD pattern for (a) CdS thin film by CBD; (b) CdS thin film by Green-CBD.

\section{Result and discussion}

\section{Crystallographic properties}

Crystallographic studies of as synthesized CdS thin films from both rout were carried out using the X-ray Diffractometer Fig. 1 shows XRD pattern of CdS thin films prepared in ammonia and lemon extract solution, the peaks observed at $2 \theta$ values of $26.65,43.98$ and 52.21 due to (111), (220) and (311) planes respectively corresponds to face centered cubic phase of CdS (zinc blend) (JCPDS card no. 89-0440). The broadening of peak observed for CdS thin film material synthesized by Green-CBD as compared to CBD method. This indicates decrease in crystalline size with respect to FWHM of spectrum. The lattice parameter ' $a$ ' and crystalline size of material has been calculated by using following equations.

$$
\begin{gathered}
\frac{1}{d^{2}}=\frac{h^{2}+k^{2}+l^{2}}{a^{2}} \\
D=K \lambda / \beta \cos \theta
\end{gathered}
$$

The crystalline size (D) of CdS has been calculated by using Scherrer's formula, Where K is constant $(0.94)$, $\lambda=1.54184 \mathrm{~A}^{\circ}$ is the wavelength, $\beta$ is broadening of diffraction line measured at half of its maximum intensity (FWHM) (in rad) and $\theta$ is Bragg's diffraction angle (in rad). The lattice parameter ' $a$ ' for CdS thin films materials were found to be in the order of $5.8323 \mathrm{~A}^{\circ}$ and $5.8113 \mathrm{~A}^{\circ}$. The crystallite size was calculated as $40 \mathrm{~nm}$ for CdS thin films synthesized by CBD in ammonia solution and $20 \mathrm{~nm}$ for $\mathrm{CdS}$ thin films prepared by Green-CBD method in lemon 
Table 1. Comparison of 2theta values, interplanar spacing (d), lattice constant (a) and crystalline size (D) of CdS thin film synthesized by CBD and Green-CBD rout.

\begin{tabular}{|c|c|c|c|c|c|c|c|c|c|c|}
\hline Sample & & $\theta$ Values & & $\begin{array}{c}\text { hkl } \\
\text { planes }\end{array}$ & $d-v$ & $\mathrm{~A}^{\circ}$ & Lattic & nstant & & $\begin{array}{l}\text { size } \\
\text { ) }\end{array}$ \\
\hline \multirow{5}{*}{$\mathrm{CdS}$} & \multirow[t]{2}{*}{ Standard } & \multicolumn{2}{|c|}{ Observed } & & \multicolumn{2}{|c|}{ Observed } & \multicolumn{2}{|c|}{ Observed } & \multicolumn{2}{|c|}{ Observed } \\
\hline & & $\begin{array}{l}\mathrm{CdS} \\
\text { (a) }\end{array}$ & $\begin{array}{c}\mathrm{CdS} \\
\text { (b) }\end{array}$ & & $\begin{array}{l}\mathrm{CdS} \\
\text { (a) }\end{array}$ & $\begin{array}{c}\mathrm{CdS} \\
\text { (b) }\end{array}$ & $\begin{array}{l}\mathrm{CdS} \\
\text { (a) }\end{array}$ & $\begin{array}{r}\mathrm{CdS} \\
\text { (b) }\end{array}$ & $\begin{array}{l}\mathrm{CdS} \\
\text { (a) }\end{array}$ & $\begin{array}{l}\mathrm{CdS} \\
\text { (b) }\end{array}$ \\
\hline & 26.50 & 25.781 & 26.613 & 111 & 3.4570 & 3.3496 & \multirow{3}{*}{$\mathrm{a}=5.8323$} & \multirow{3}{*}{$\mathrm{a}=5.8113$} & \multirow{3}{*}{40} & \multirow{3}{*}{20} \\
\hline & 43.96 & 43.404 & 43.923 & 220 & 2.0848 & 2.0614 & & & & \\
\hline & 52.13 & 51.806 & 52.032 & 311 & 1.7647 & 1.0670 & & & & \\
\hline
\end{tabular}

extract. The values of lattice parameters were presented in Table 1 [26]. From literature studies it has been observed that the CdS thin film materials synthesized by CBD using ligand such as isopropyl xanthate at $\mathrm{pH} 10$ shows cubic phase orientation along (111) with average grain size of 78 $\mathrm{nm}$. As synthesized CdS material using biomolecule ligand has average grain size of $20 \mathrm{~nm}$ with decrease in band gap energies $[\mathbf{2 7 , 2 8}$.

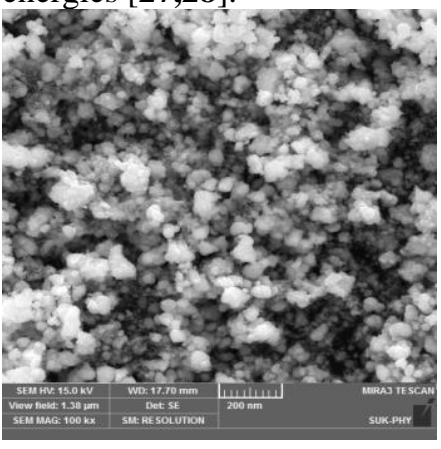

(a)

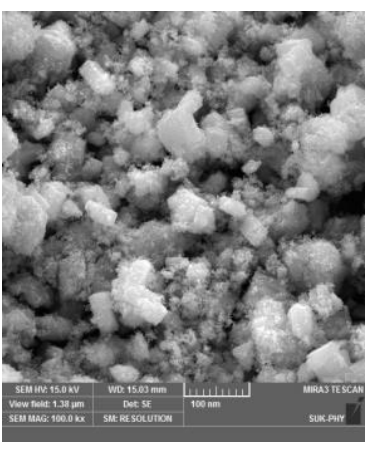

(b)
Fig. 2. SEM images of a) CdS thin films by CBD method b) CdS thin films by Green-CBD method.

\section{Surface morphology and elemental analysis of thin films}

The scanning electron microscopy (SEM) was used for analysis of morphology of CdS thin film materials shown in Fig. 2. The $\mathrm{CdS}$ thin film material shows nanospheres and nanocubes for CBD and Green-CBD methods respectively. The elemental compositions were determined by energy dispersive X-ray analysis (EDAX) for thin film prepared from Green-CBD method shown in Fig. 3 with the atomic percentage of $\mathrm{Cd}(\mathrm{L})$ is $52.04 \%$ and $\mathrm{S}(\mathrm{L})$ is 47.96 $\%$ presented in Table 2 coinciding to those percentage compositions of $(1: 1$ of $\mathrm{Cd}: \mathrm{S})$ for synthesis of thin films.

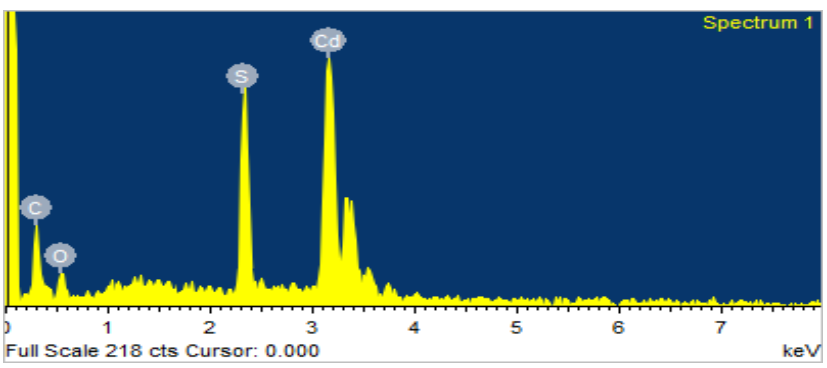

Fig. 3. EDAX spectrum of CdS thin film by Green-CBD method showing elemental composition.
Table 2. Element composition (EDAX analysis) of CdS Thin film synthesized by Green-CBD rout.

\begin{tabular}{ll}
\hline Element & Atomic\% \\
\hline $\mathrm{Cd} \mathrm{L}$ & 52.04 \\
$\mathrm{~S} \mathrm{~L}$ & 47.96 \\
\hline Totals & 100.00 \\
\hline
\end{tabular}

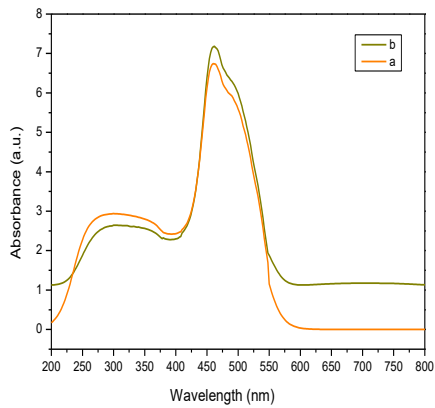

(a)

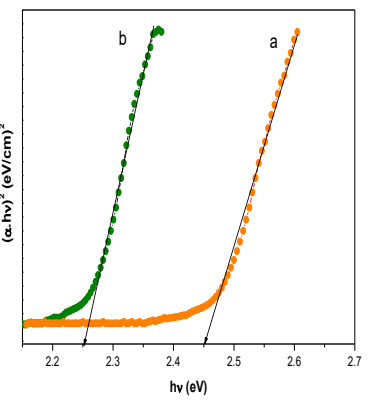

(b)
Fig. 4. UV-Visible absorption spectra a) Graph of Absorbance against wavelength to absorption maxima of CdS thin films b) Graph of ( $\alpha$ hv $)^{2}$ against (hv) to direct allowed band gap energy of CdS thin films.

\section{Optical properties of thin films}

The optical absorption analysis for thin films were carried out with UV-Vis-NIR double beam spectrophotometer using the data obtained from the optical absorption spectra It has been shown the absorption maxima in UV and visible region. The CdS thin film synthesized by CBD and Green$\mathrm{CBD}$ has absorption maxima in visible region in comparison. The synthesized $\mathrm{CdS}$ thin film materials absorbs visible light more efficiently than UV light. The optical energy band gap, Eg of CdS thin films were estimated by plot of $(\alpha h v)^{2}$ against the photon energy (hv). In order to gets the value of the direct allowed optical band gap (Eg), extra plotting the straight line to intercept photon energy axis which gives values of band gap energy (Eg). As synthesized CdS thin films has observed value of band gap energy in order of $2.45 \mathrm{eV}$ and $2.25 \mathrm{eV}$ for CBD and GreenCBD shown in Fig. 4. Photoluminescence (PL) spectrum of $\mathrm{CdS}$ thin films materials shows quenching of peak intensity with red shift for the materials synthesized by Green-CBD wrt CBD shown in Fig. 5. The absorption maximum shifts to the visible region with hole-charge recombination [29]. 


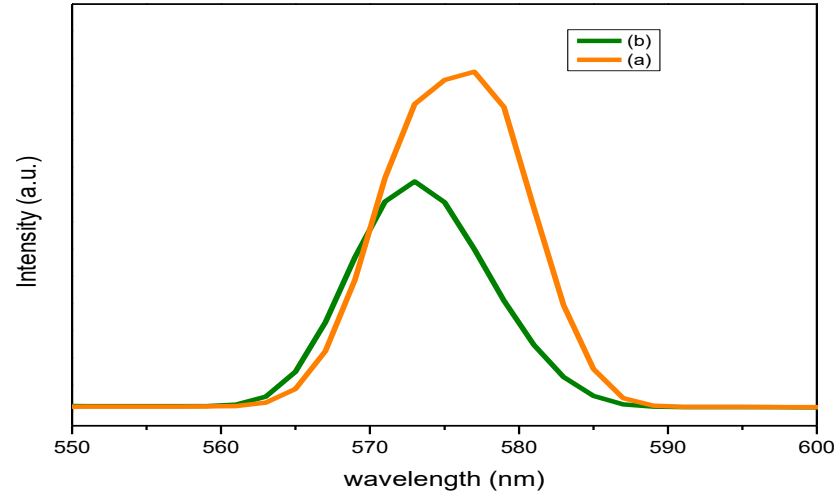

Fig. 5. Photoluminescence (PL) spectra for CdS thin films by CBD and Green-CBD

\section{Photocatalytic degradation of Rhodamine-B dye}

The photo catalytic activity of CdS thin films were studied against Rhodamine-B under natural sunlight irradiation. For that as synthesized CdS thin film was dipped in $100 \mathrm{~m}$ of $15 \mathrm{ppm}$ Rhodamine-B dye solution in $250 \mathrm{ml}$ reaction container. Before irradiation to sunlight, the solution was kept in the dark for at least $4 \mathrm{hr}$ allowing the adsorption/desorption equilibrium to be reached. Then, the solution was kept under solar light irradiation of average intensity of $8.67 \mathrm{kWhr} / \mathrm{m}^{2}$-day in summer [30]. The arrangement done as maximum sunlight falls on thin film surface in solution. First sample was taken before the irradiation to obtain dark adsorption, which was after considered as the initial concentration $\left(\mathrm{A}_{\text {initial }}\right)$. Samples were then withdrawn regularly from the reaction container by an order of $20 \mathrm{~min}, 40 \mathrm{~min}, 60 \mathrm{~min}, 80 \mathrm{~min}$ and $100 \mathrm{~min}$ as final $\left(\mathrm{A}_{\text {final }}\right)$. The solution was then analyzed by using a UV-Vis-NIR spectrophotometer at wavelength range from 400 to $800 \mathrm{~nm}$. The efficiency of material was calculated by using following equation [31-33].

$$
\operatorname{Efficiency}(\%)=\frac{\left[A_{\text {initial }}-A_{\text {final }}\right]}{A_{\text {initial }}} \times 100
$$

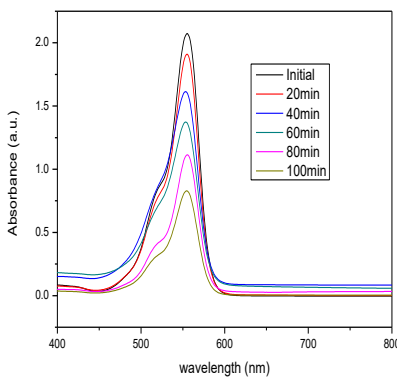

(a)

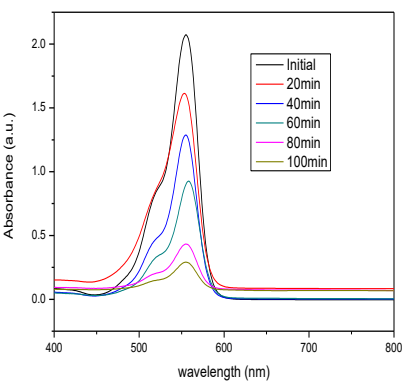

(b)
Fig. 6. UV-Visible absorbance spectrum for photodegradation of Rhodamine-B dye using (a) CdS thin films by CBD method (b) CdS thin films by Green-CBD method.

It was observed that $\mathrm{CdS}$ thin films synthesized by Green-CBD have more efficiently degrades Rhodamine-B dye solution than films synthesized by CBD method shown in Fig. 6. The free electrons probably react with dissolved oxygen molecules and produce oxygen peroxide radical $\mathrm{O}_{2} \bullet-$ the positive charged hole $(\mathrm{h}+)$ may react with the $\mathrm{OH}$ - derived from $\mathrm{H}_{2} \mathrm{O}$ to form hydroxyl radical $\mathrm{OH} \bullet$. The Rhodamine- $\mathrm{B}$ molecule then can be photo catalytically degraded by oxygen peroxide radical $\mathrm{O}_{2} \bullet$ - and hydroxyl radical $\mathrm{OH} \bullet$ to forms $\mathrm{CO}_{2}, \mathrm{H}_{2} \mathrm{O}$ and other mineralization products $(\mathrm{P})$. The reaction kinetics was studied by plotting of \% Efficiency $(\eta)$ against Time $(\mathrm{T})$ for the degradation of Rhodamine-B solution using $\mathrm{CdS}$ thin films. Fig. $7[34,35]$.

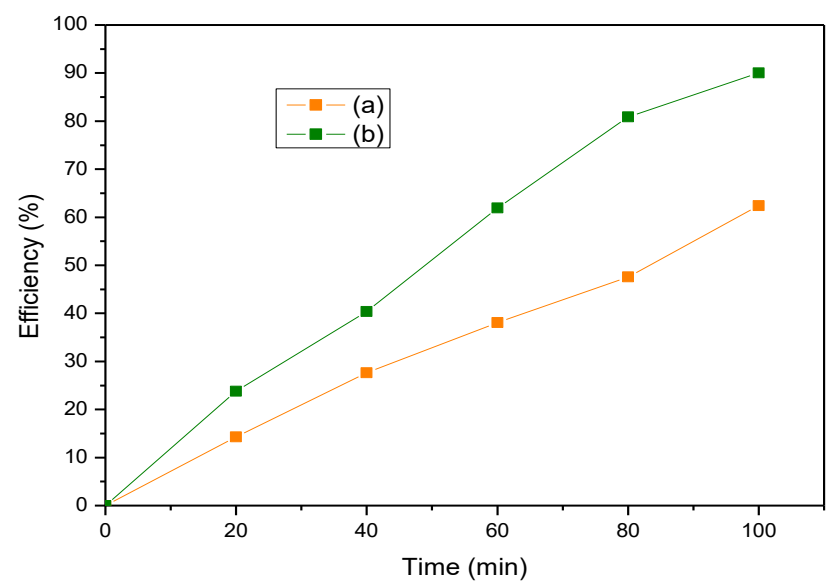

Fig. 7. Graph of \% efficiency against time for degradation of RhodamineB using CdS thin films.

\section{Conclusions}

The CdS thin films were successfully synthesized by Green-CBD method at room temperature in Lemon extract as a stabilizing/capping agent. It gives $\mathrm{CdS}$ nanocubes with average size of $20 \mathrm{~nm}$. The Green-CBD synthesis avoids the use of toxic precursors, volatilization of ammonia solution and elevated temperature conditions. As synthesized CdS thin films in CBD and Green-CBD methods has face centered cubic phase predominantly with considerable optical band gap energy of $2.45 \mathrm{eV}$ and 2.25 $\mathrm{eV}$ respectively. The CdS thin films efficiently degrade Rhodamine-B dye solution under natural sunlight irradiation. The CdS thin materials synthesized by GreenCBD has smaller crystalline size than CBD. The degradation efficiency is more for $\mathrm{CdS}$ thin films prepared in Green-CBD as compared to CBD.

\section{Acknowledgements}

The authors are thankful to SAIF, IIT-Mumbai, India for providing electron microscopic characterizations and acknowledge the support of Principal, Government Rajaram College, Kolhapur, MS, India for motivational support and providing laboratory facility during this research work.

\section{Keywords}

Thin films; Green-CBD method; nanocubes; optical band gap; photodegradation.

Received:

Revised:

Accepted: 


\section{References}

1. $\quad$ Kariper I.A.; Materials Research, 2017, 20, 1345.

2. Chate, P.A.; Patil, S.S.; Patil, J.S.; Sathe, D.J.; Hankare, P.P.; Physica B Condense Matter, 2013, 411, 118.

3. Gilic, M.; Trajic, J.; Romcevic, N.; Romcevic, M.; Timotijevic, D.; Stanisic, G.; Yahia, I.; Optical Materials, 2013, 35, 1112.

4. Tezel, N.S.; Tezel, F.; Kariper, I.A.; Applied Physics A, 2019, 125, 1.

5. Nakanishi, T.; Ito, K.; Solar Energy Materials and Solar Cells, 1994, 35, 171.

6. Fainer, N.I.; Kosinova, M.L.; Rumyantsev, YuM; Salman EG; Kuznetsov FA; Thin Solid Films, 1996, 280, 16.

7. Guneri, E.; Kariper, I.A.; Journal of Alloys and Compounds, 2012, 516, 20.

8. Kariper, I.A.; Progress in Natural Science: Materials International, 2014, 24, 663.

9. Gode, F.; Yavuz, F.; Kariper, I.A.; Acta Physica Polonica A, 2015, 128,215

10. Kariper, I.A.; Spectrochimica Acta Part A: Molecular and Biomolecular Spectroscopy, 2016, 163, 102.

11. Selma, M.H.; AL-Jawad; Ali A.T.; Abdulah Mohammed Redha; Natheer Jamal Imran; Surface Review and Letters, 2021, 28, 1.

12. Ali A.T.; Selma, M.H.; AL-Jawad; Abdulah Mohammed Redha; Modern Physics Letters, 2019, B 33, 195.

13. Selma, M.H.; AL-Jawad; Ali, A.T.; Abdulah Mohammed Redha; Journal of Sol-Gel Science and Technology, 2019, 91, 310

14. Soundeswaran, S.; Kumar, O.S.; Dhanasekaran, R.; Materials Letters, 2004, 58, 2381

15. Zhao Xiang Hui; Wei Ai Xiang; Zhao Yu; Liu Jun; Journal of Materials Science: Materials in Electronics, 2013; 24, 457.

16. Kumarage, WGC; Wijesundera, R.P.; Seneviratne, V.A.; Jayalath, C.P.; Varga, T.; Nandasiri, M.I.; Dassanayake, B.S.; Material Chemistry and Physics, 2017, 200, 1.

17. Hadia, K.J.; Nwar, A.Y.; Selma, M.H.; AL-Jawad; Journal of SolGel Science and Technology, 2021, 97, 48.

18. Wei Qinglian; Kang Shi-Zhao; Mu Jin; Colloids and Surfaces A: Physicochem. Eng. Aspects, 2004, 247, 125.

19. Borovaya, M.N.; Naumenko, A.P.; Matvieieva, N.A.; Blume, Y.B.; Yemets, A.I.; Nanocsale Res. Lett., 2014, 9, 1.

20. Borovaya, M.N.; Burlaka, O.M.; Naumenko, A.P.; Blume, Y.B.; Yemets, A.I.; Nanoscale Res. Lett., 2016, 11, 1.

21. Prasad, K.; Jha, A.K.; Journal of Colloid and Interface Science, 2010, 342, 68

22. Sawant, V.J.; Sensing and Bio-Sensing Research, 2019, 27, 100314.

23. Prathnaa, T.C.; Chandrasekarana, N.; Raichur, A.M.; Mukherjeea, A.; Colloids and Surfaces B: Biointerfaces, 2011, 82, 152.

24. Apte, S.K.; Kale, B.B.; Sonawane, R.S.; Naik, S.D.; Bodhale, S.S.; Das, B.K.; Materials Letters, 2006, 60, 499.

25. Khomane, A.S.; Journal of Alloys and Compounds, 2010, 496, 508.

26. Senasu, T.; Nanan, S.; J. Mater. Sci.: Mater Electron, 2017, 28, 17421.

27. Kariper, A.; Guneri, E.; Gode, F.; Gumus, C.; Ozpozan, T.; Materials Chemistry and Physics, 2011, 129, 183.

28. Kariper, A.; Guneri, E.; Gode, F.; Gumus, C.; Chalcogenide Letters, 2012, 9, 27.

29. Yu, Z.; Yin, B.; Qu, F.; Wu, X.; Chem. Eng. J., 2014, 258, 203.

30. Jamil, B.; Siddiqui, A.T.; Akhtar, N.; Engineering Science and Technology an International Journal, 2016, 19, 1826.

31. Rahman, Q.I.; Ahmad, M.; Misra, S.K.; Lohani, M.; Mater Lett., $\mathbf{2 0 1 3}, 91,170$

32. Kavi, J.; Alshahrie, A.; Periyat, P.; Nano Structures and Nano Objects, 2018, 16, 24.

33. Saleh, T.A.; Gupta, V.K.; Journal of Colloid and Interface Science, 2011, 362, 337.

34. Lavate, D.A.; Sawant, V.J.; Khomane, A.S.; Chemical Papers, 2020, 74,879 .

35. Sawant, V.J.; Lavate, D.A.; Khomane, A.S.; IJC-A, 2020, 59, 1084. 